Original Research Paper

\title{
Using 3D Virtual Environment as an Educational Tool in a Middle Eastern University
}

\author{
${ }^{1}$ Ahmad F. Shubita and ${ }^{2}$ Ghassan F. Issa \\ ${ }^{1}$ Department of Software Engineering, University of Petra, Amman, Jordan \\ ${ }^{2}$ Department of Computer Science, University of Petra, Amman, Jordan
}

\author{
Article history \\ Received: 03-01-2019 \\ Revised: 30-05-2019 \\ Accepted: 23-10-2019 \\ Corresponding Author: \\ Ahmad F. Shubita \\ Department of Software \\ Engineering, University of \\ Petra, Amman, Jordan \\ Email: ashubita@uop.edu.jo
}

\begin{abstract}
A virtual environment can be anything the users desire it to be; it is their personal, virtual life. Many people cannot physically attend college to undertake their degrees. Even though many educational institutions are providing online courses and degrees, these are still not as interactive as in real life. By using a 3-D virtual environment for educational purposes, users can interact via their own graphical and humanoid selfrepresentations, known as 'avatars'. The virtual world Second Life is used in this research as instructors can use SL to communicate with students and to create objects that can be used to teach course content and skills. The idea of using a virtual environment for educational purposes will involve building a virtual land for the Faculty of IT at one of the universities in Jordan (Petra University). This will enable anyone to virtually access and communicate with the faculty from anywhere in the world. This virtual campus will help solve students' problems, providing details about the content and services the faculty provides, support the social awareness of students and increase communication and discussions on a wide scale.
\end{abstract}

Keywords: Virtual Environments, Second Life, Education, Virtual Land, Middle East, Virtual Campus

\section{Introduction}

The University of Petra (UOP) Virtual Campus is a place in Second Life (SL) where the realities of studying, teaching and communicating are combined with the virtual world. This project will allow students to take courses and classes and communicate and interact with other students and teachers in a virtual environment. Creating a UOP virtual campus is a huge opportunity for many people who cannot physically come to college to take their degree. Even though many educational institutions are providing online courses and degrees, these are still not as interactive as in real life. That is why creating a college in Second life allows the person to imagine they are attending an actual class with other students and allows them to have a presence in the virtual campus.

Living with technology has become a norm of everyday life. The Internet is everywhere and society is connected in more ways than one. Most people have a physical presence as well as a virtual presence. The Internet has allowed people to be connected and have strong relationships with each other using social media platforms. For the past few years, a new technology has been evolving and getting more attention in many fields: Virtual Reality (VR). The main purpose of VR is to create a world where all the users are immersed and represented by avatars that deal with one another in a realistic fashion (Shubati et al., 2010). With the increasing popularity of virtual worlds and environments, 3D virtual environments continue to be investigated and developed for educational purposes (Wang, 2013).

\section{Second Life}

Since its launch in 2003 by Linden Lab, SL has gained a massive number of users who can create avatars and interact with one another in a virtual setting (Alenezi and Shahi, 2015). An avatar (Fig. 1) is a visual representation of the user that can be used for real-time interactions and to build virtual spaces and objects using virtual dollars (Linden Dollar). Users can personify their avatars through a user-friendly interface (Varvello, 2011; Memikoğlu, 2014). Moreover, in SL, avatars have the ability rent or own land and can be setup to reflect a user's needs or specifications (Wright and Wilhelmina, 2011). 
SL has two types of land regions: Mainland and islands that are considered as individual regions (Shubati et al., 2011). Users, especially instructors, can build any object on their owned property using the Linden scripting language to help them teach abstract objects to their students (Wright and Wilhelmina, 2011; Merchant, 2014).

SL is currently the most mature and popular 3D Multi-User Virtual Environment (MUVE) being used in education around the world. One of the reasons for making VR technologies available and accessible is the advances in technology and in low-cost devices, such as headphones (Merchant, 2014). According to Alenezi and Shahi (2015), many people live in remote places or with no proper communication systems, or are physically challenged and not able to attend a physical educational place. Therefore, they seek an alternative option to receive their desired degree or certificate.

One of the most popular options is learning online and with an interactive place, this becomes an even better option. It is also efficient and helpful to make course materials ubiquitously available (Alenezi and Shahi, 2015). Also, a sense of presence is developed in the students who feel as if they are physically present in the educational centre and who spend time with their instructors/professors and peers if they have questions or problems (Alenezi and Shahi, 2015). The e-learning programs in SL that facilitate communication tools also encourage collaborative activities between instructors and students by permitting an interaction between them with real-time feedback (Gallego, 2016; Vincent, 2017).

Even with all the benefits SL provides, however, there are also some drawbacks. SL can be easy to use and helps users design and visualize objects, but users still need skills and abilities to use this software. For example, most of the time, SL needs high-speed internet availability to operate correctly and efficiently (Shubati et al., 2009). The most obvious drawback of SL is the time it takes to obtain the skills needed to create objects and interact with others. In some cases, it takes time to create projects which need learning first and then applied (Alenezi and Shahi, 2015). In a previous research study looking at the use of SL for educational purposes, they concluded that the investment in learning time was the biggest drawback (Wright and Wilhelmina, 2011). The students needed time to learn how to operate within SL and the instructors needed to employ new skills and techniques. In this study, it took the students and teachers around three hours to learn the fundamental skills needed for SL (Wright and Wilhelmina, 2011).

\section{Second Life for Educational Purposes}

In the field of education, the idea of implementing VR in schools and higher education began in the early 1990s. As VR is interactive, it needs the involvement of many devices, such as head-mounted display gears, data gloves and body suits to create a fully immersive learning experience that imitates a real-life process or situation. This then enables the individual to visualise and interact with a virtual 3D environment in real time (Merchant, 2014; Memikoğlu, 2014; Boulos, 2008). There have been many problems in the past that have stopped researchers from continuing with their projects, however, such as strain injuries and physical and psychological discomfort (Merchanto, 2014; Varvello, 2009).

Nowadays, the rise of desktop-based VR technology has enhanced the $3 \mathrm{D}$ visualisation experience. Therefore, many educators and instructors are integrating this technology into their practice (HKPU, 2011). The reason for this lies with the benefits this technology provides to the students as it uses interactive digital learning environments to teach abstract concepts and to enhance the learners' cognitive skills.

From an educational point of view, SL has become increasingly popular over the past two decades (Wang, 2013). As of 2016, the education sector makes up around five percent of the lands in SL and the number of colleges and educational institutions in SL is around 500 (Ketelhut, 2006; Alenezi and Shahi, 2015; Gallego, 2016). Due to the success of this tool, millions of dollars have been invested in educational virtual environments.

\section{Case Study: UOP Virtual Campus}

Having an online presence has become essential for many companies and organisations, including those in the educational sector, but having a virtual presence is a relatively new concept. SL is a new technology in the Middle East, but has a lot of potential if implemented correctly. The UOP Virtual Campus is a place in Second Life where the reality of studying, teaching and communicating is combined with the virtual world.

Creating a UOP Virtual Campus is a huge opportunity for many people who cannot physically come to college to take their degree. Even though many educational institutions provide online courses and degrees, these are as interactive as real life. Creating a college in SL would allow users to imagine they are attending an actual class with other students and give them a presence in the virtual college.

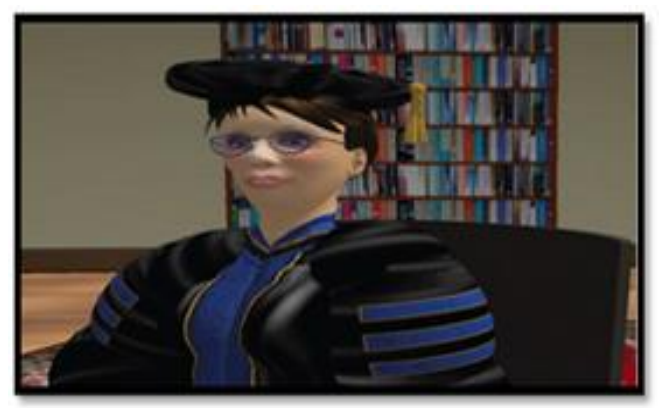

Fig. 1: Second Life education: Virtual learning (Linden Lab, 2011) 


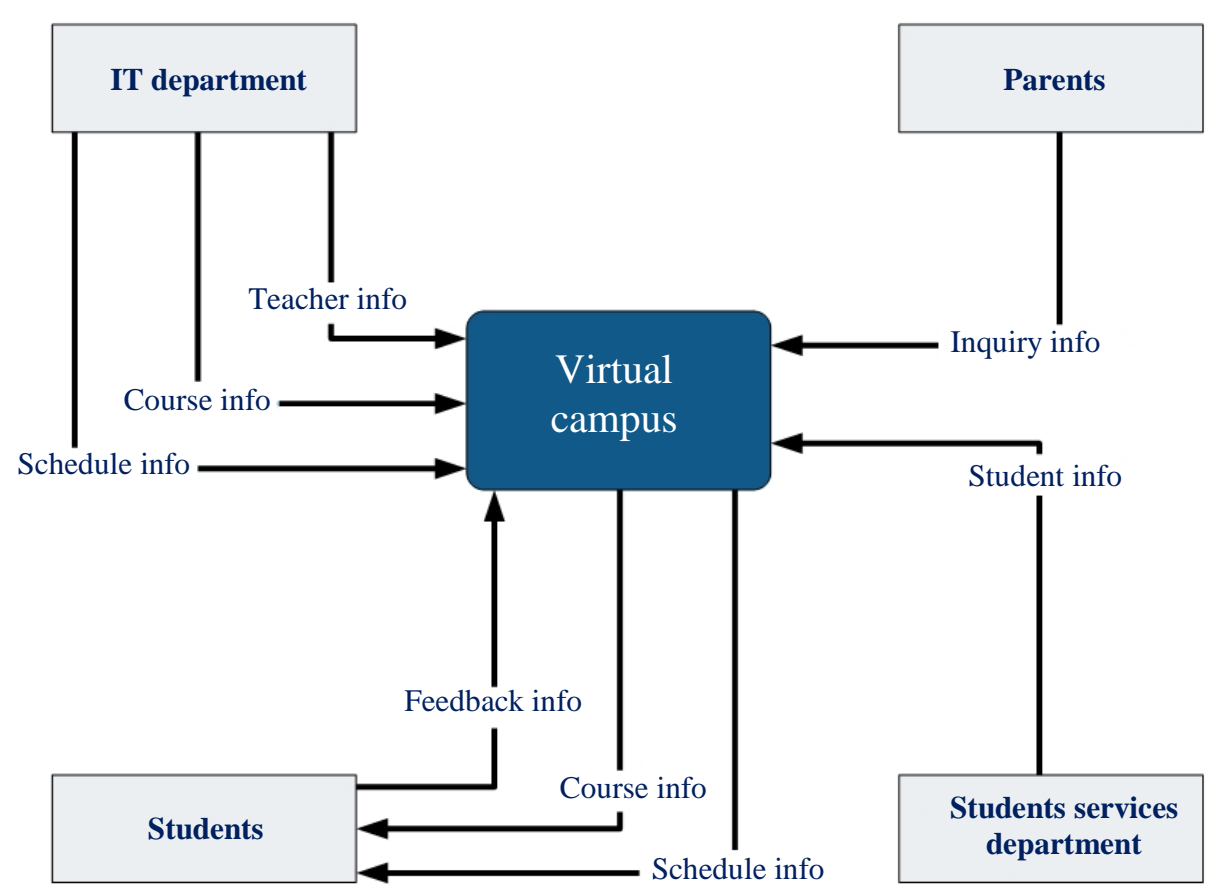

Fig. 2: A scope model of the UOP virtual campus

\section{Virtual Campus: Characteristics and Requirements}

UOP Virtual College is a land in SL where people from many places can gather together for educational purposes. The college campus will provide facilities to visitors, parents, the faculty and most importantly, the students. Some of the requirements of the campus as shown in Fig. 2 to 4 include:

- The virtual college receiving course information from the IT department

- The virtual college receiving teacher information from the IT department

- The virtual college receiving schedule information from the IT department

- The virtual college providing students with course information

- The virtual college providing students with schedule information

- The virtual college being able to receive feedback from students

- The virtual campus receiving student information from the Student Services Department

- Parents being able to visit the virtual campus when they have questions or inquiries

- The virtual campus being easy to use for students and faculty staff members

- The virtual campus' reception area displaying a banner or a poster with course information

- No one being able to enter the classroom except registered students or visiting parents/staff
Virtual Campus: Design

\section{Main Building}

The main building (Fig. 5 and 6) of the Virtual College will be placed on a flatland that has enough space for the building. The building will have at least one classroom, one staff office, a lounge area and a reception area. There must also be space to place the chairs and tables, the suggestion box and the pin board.

\section{Reception}

Figure 7 showcases how the reception of the main building might look. There will be a table with office utensils, such as a laptop and printer and there should also be chairs so it can act as a waiting area.

\section{Lounge}

Figure 8 depicts the space where students and teachers can spend their free time. It should have vending machines and lockers for students to safely store their belongings.

\section{Suggestion Box}

Figure 9 shows a suggestion box where users can put their suggestions, opinions and comments regarding any issues they may have. It will be positioned in a high-up place so users will notice it.

\section{The Classroom}

In the classroom shown in Fig. 10, there will be enough desks to suit the number of students 
Ahmad F. Shubita and Ghassan F. Issa / Journal of Computer Science 2019, 15 (10): 1498.1509 DOI: $10.3844 /$ jessp.2019.1498.1509

(approximately 16). The classroom will include a smartboard, a TV and a whiteboard.

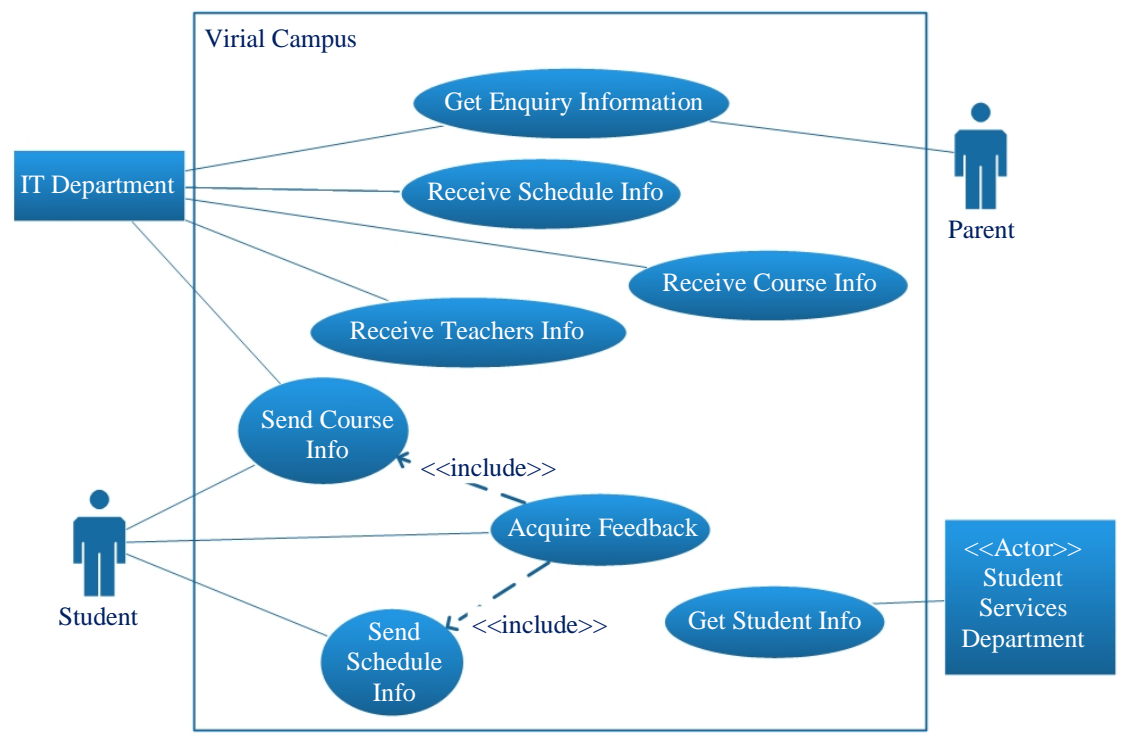

Fig. 3: A case diagram of the UOP virtual campus

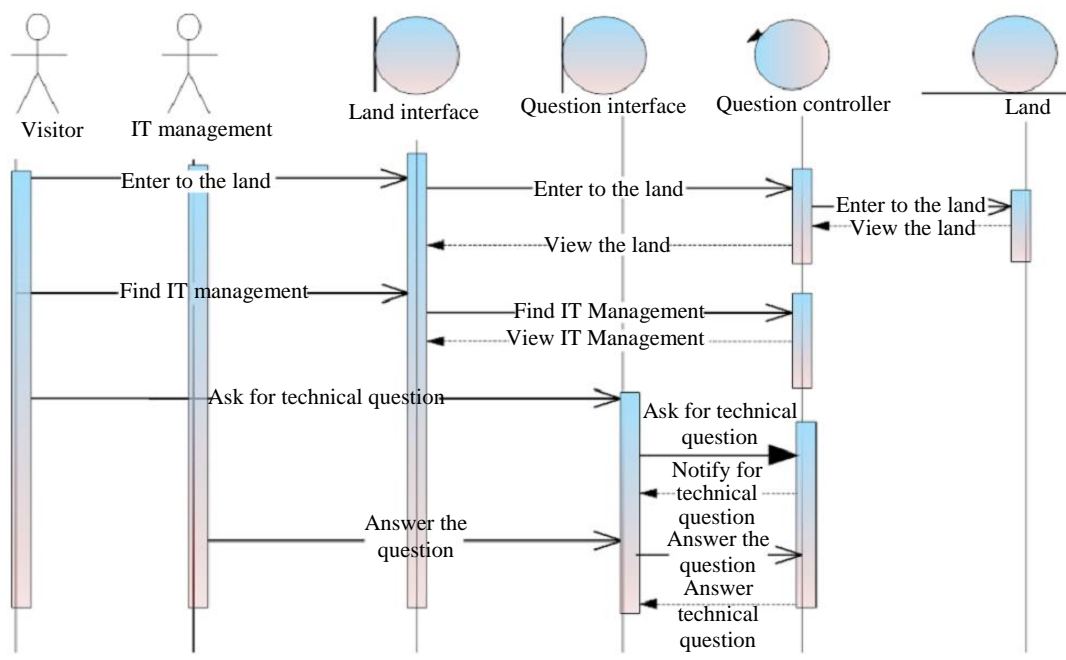

Fig. 4: A swimlane diagram of the UOP Virtual Campus

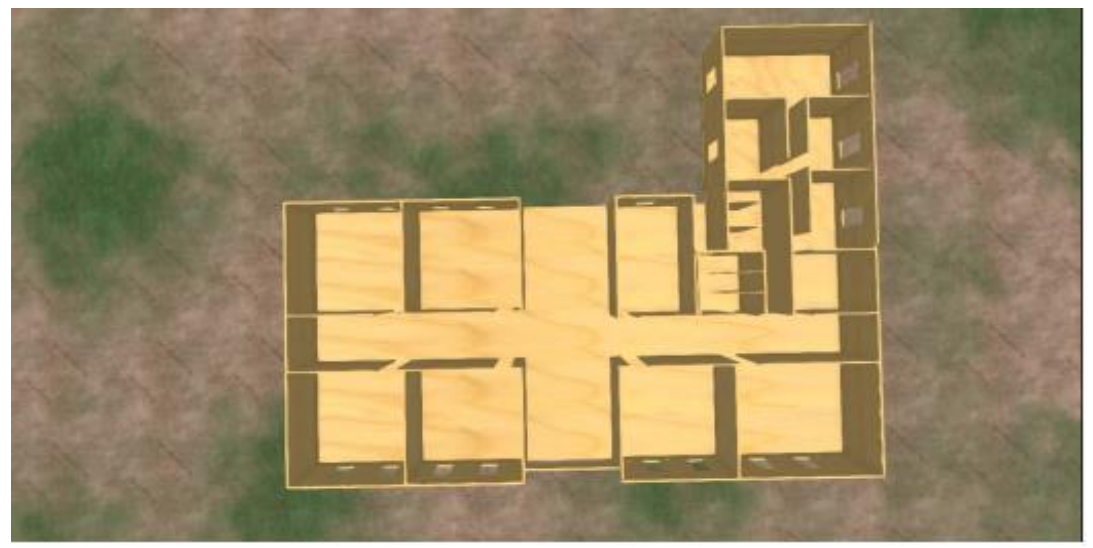

Fig. 5: A 3D computer model of the UOP Virtual College 
Ahmad F. Shubita and Ghassan F. Issa / Journal of Computer Science 2019, 15 (10): 1498.1509 DOI: $10.3844 /$ jessp.2019.1498.1509

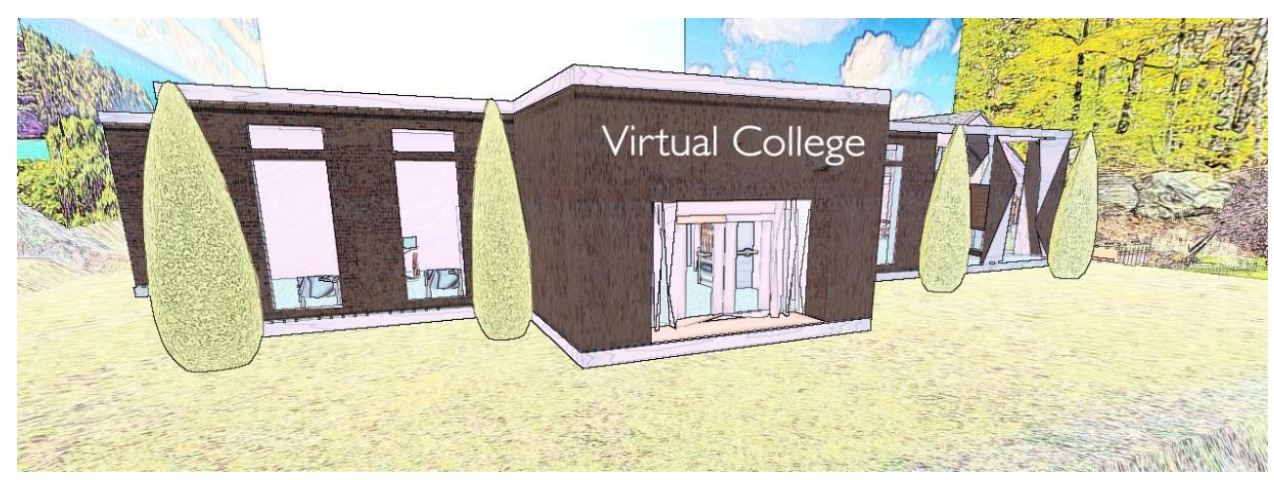

Fig. 6: A computer drawn picture of the Virtual College's main building

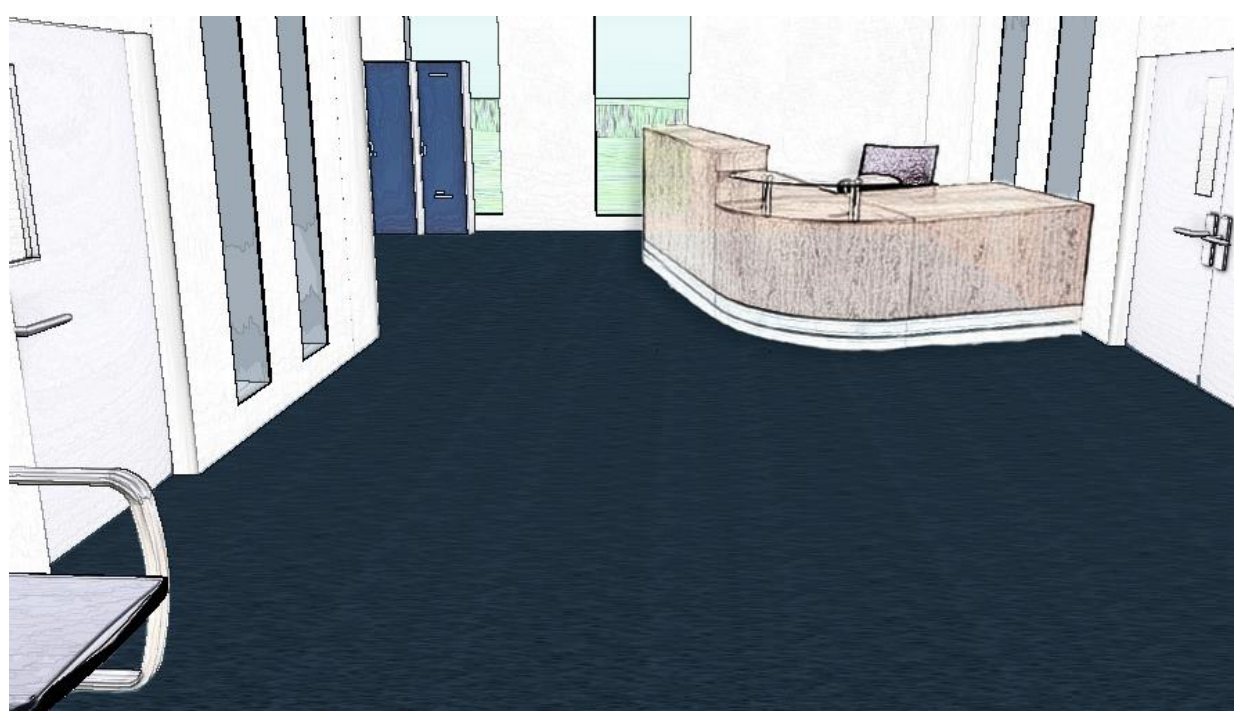

Fig. 7: A drawing of the main building's reception

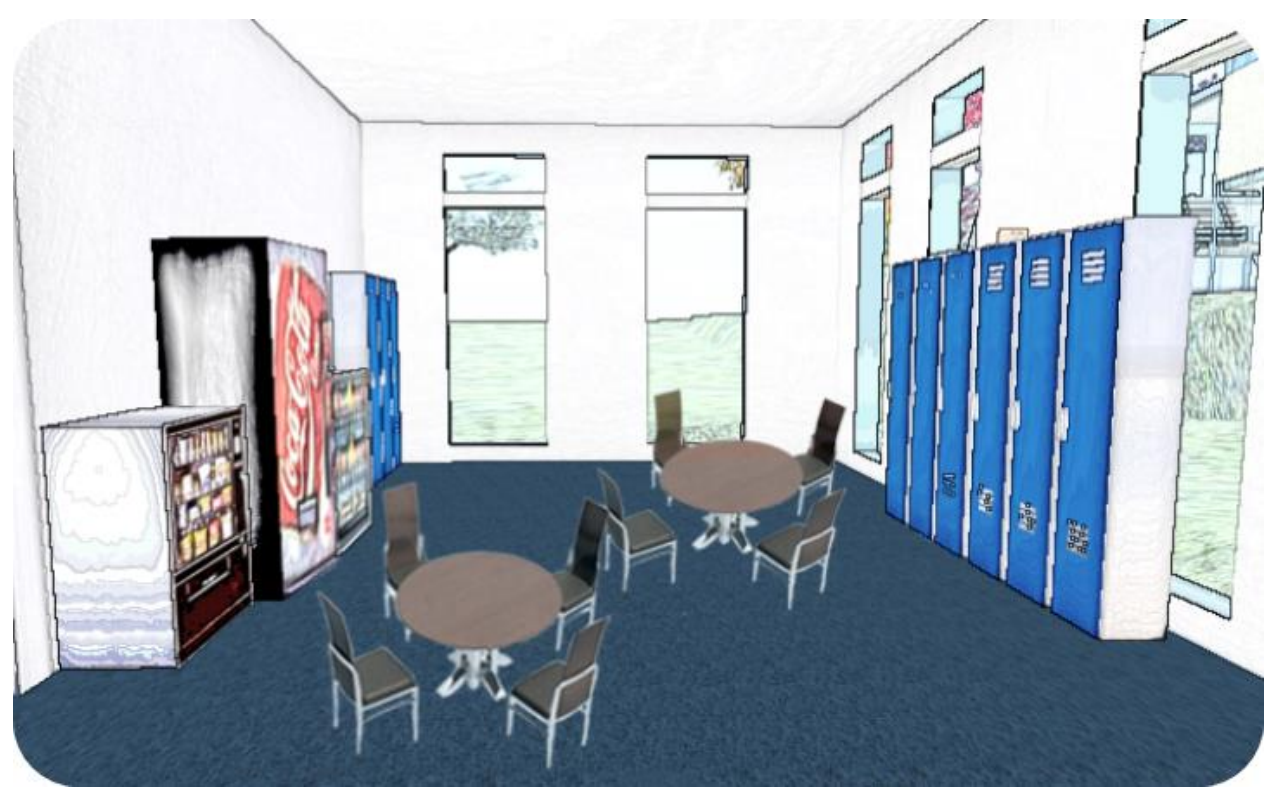

Fig. 8: A picture of the lounge area in the main building 

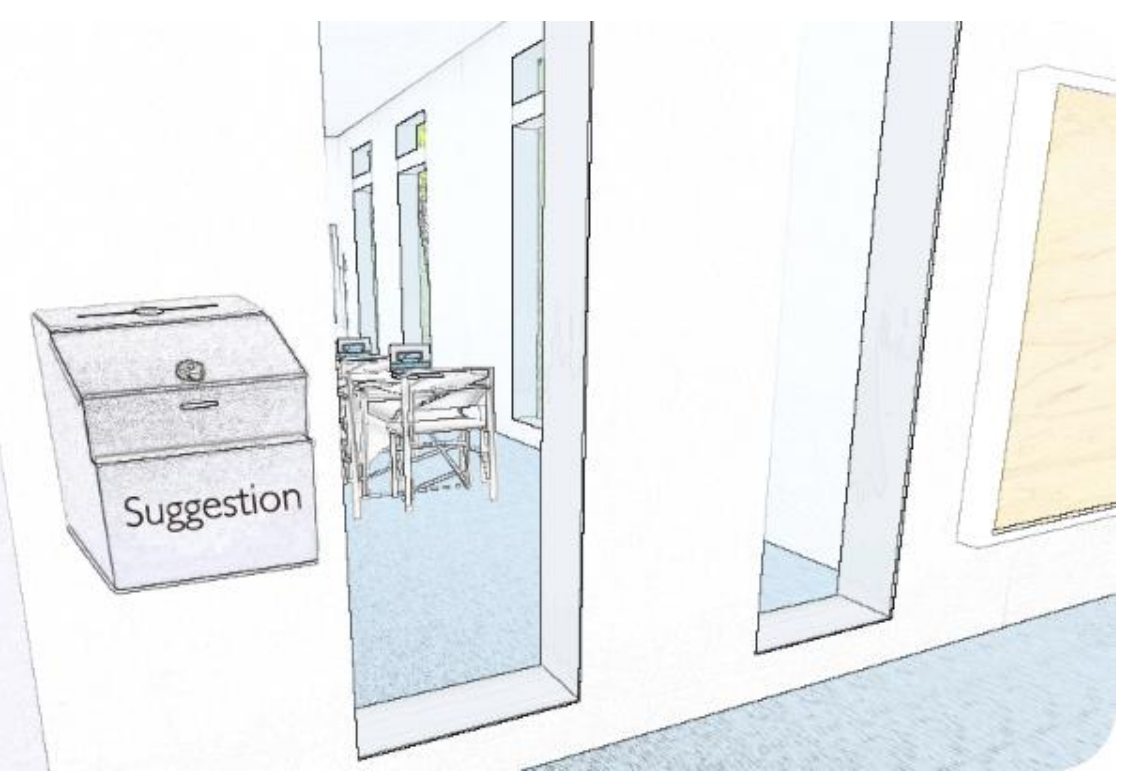

Fig. 9: A drawing showing the suggestion box placed high up on a wall

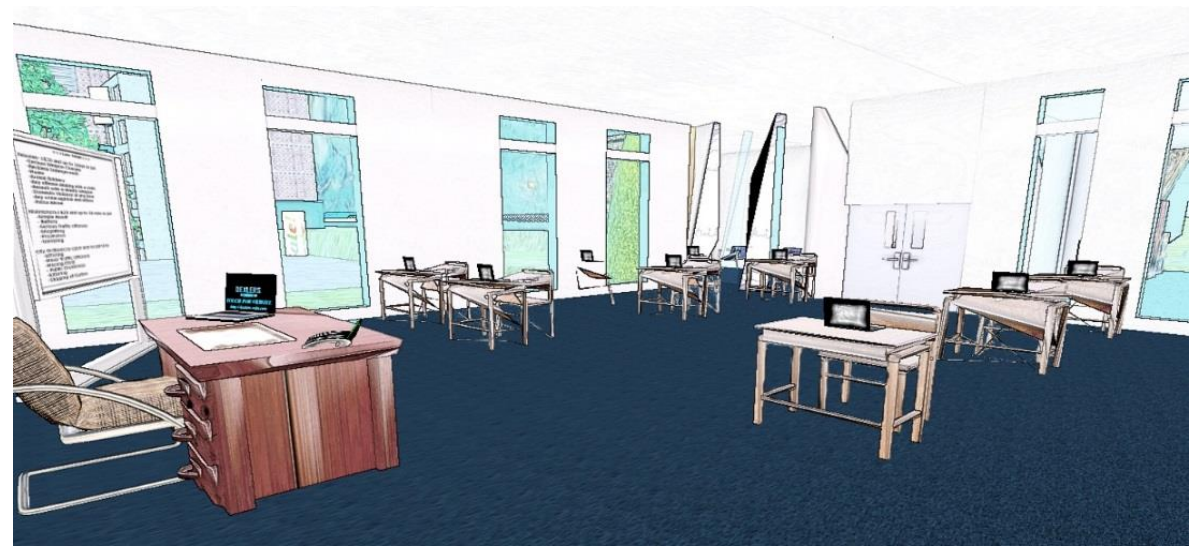

Fig. 10: A picture showing a side view of the classroom

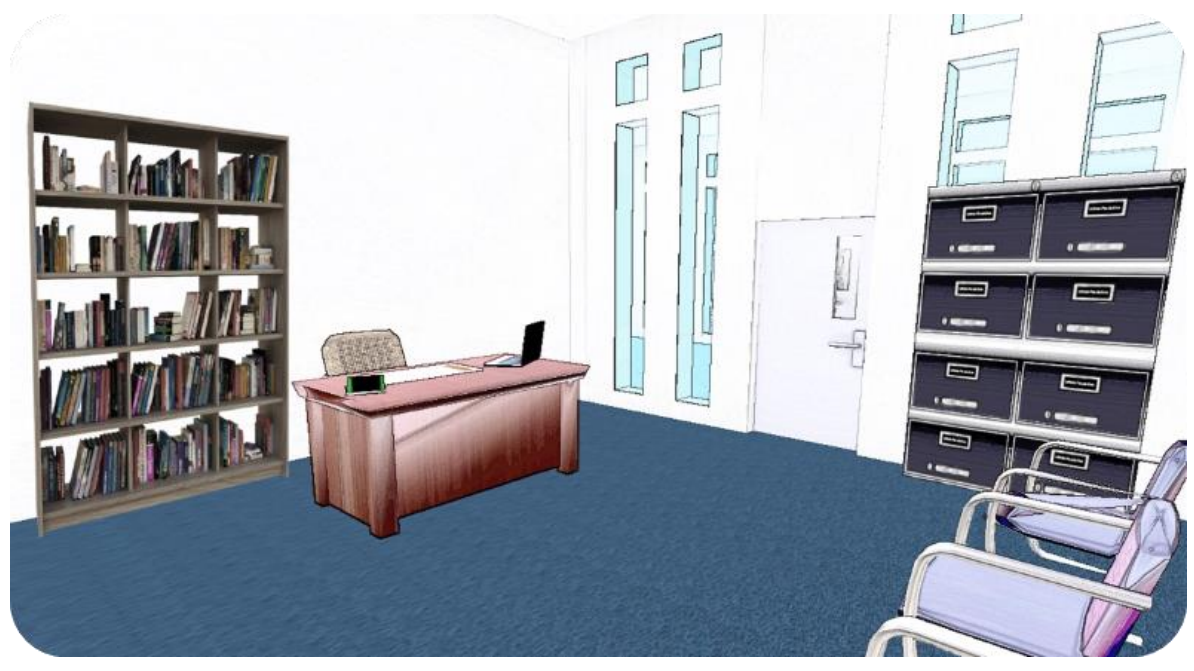

Fig. 11: A picture of the staff office 


\section{Staff Office}

The staff office should have a staff desk, a bookcase to showcase course material and a file cabinet for important files and documents (Fig. 11). There should also be some chairs for guests to sit on.

\section{Virtual Campus: Implementation and Testing}

Once the critical components are sketched, the Virtual Campus needs to be developed and built in SL. The arrangements and adjustments of the items were performed according to the sketches (Fig. 12). Several small items and accessories were brought in at the development stage to make the Virtual College look just like a real UOP campus. The Implementation of the Virtual Campus started in February and ended in May of the same year. Three months were needed to develop the Virtual Campus and another two weeks for testing.

\section{Virtual Campus: Implementation}

The building was placed on purchased land around 1,500 square meters ( 527 prims) in size. The size of the land meant it was big enough to fit the Virtual College and have space for other items around the building. There are also neighbouring lands that could be used for future expansions.

In the reception area shown in Fig. 13, there is a long desk with office equipment, a small chair for the desk and a printer.

The lounge area (Fig. 14) is where users can rest and has several vending machines. The sitting area in the lounge has two tables with four chairs each that were bought from the SL marketplace.

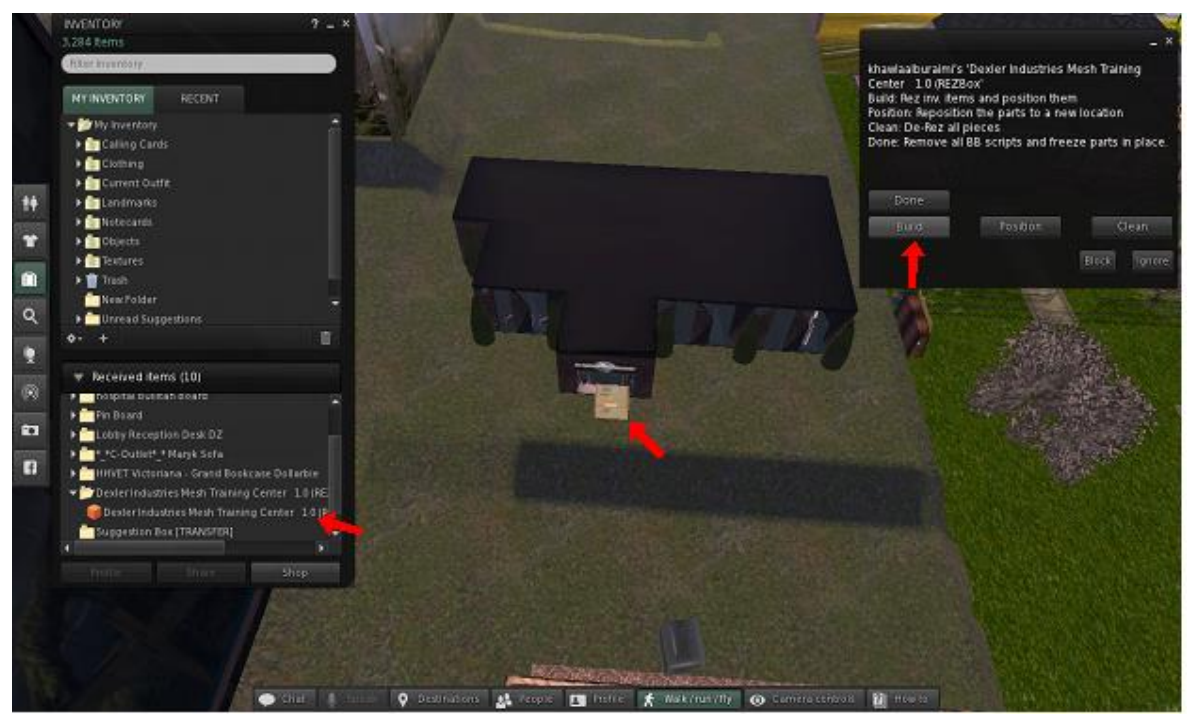

Fig. 12: A screenshot of the virtual building being placed on the land after being dragged from the inventory

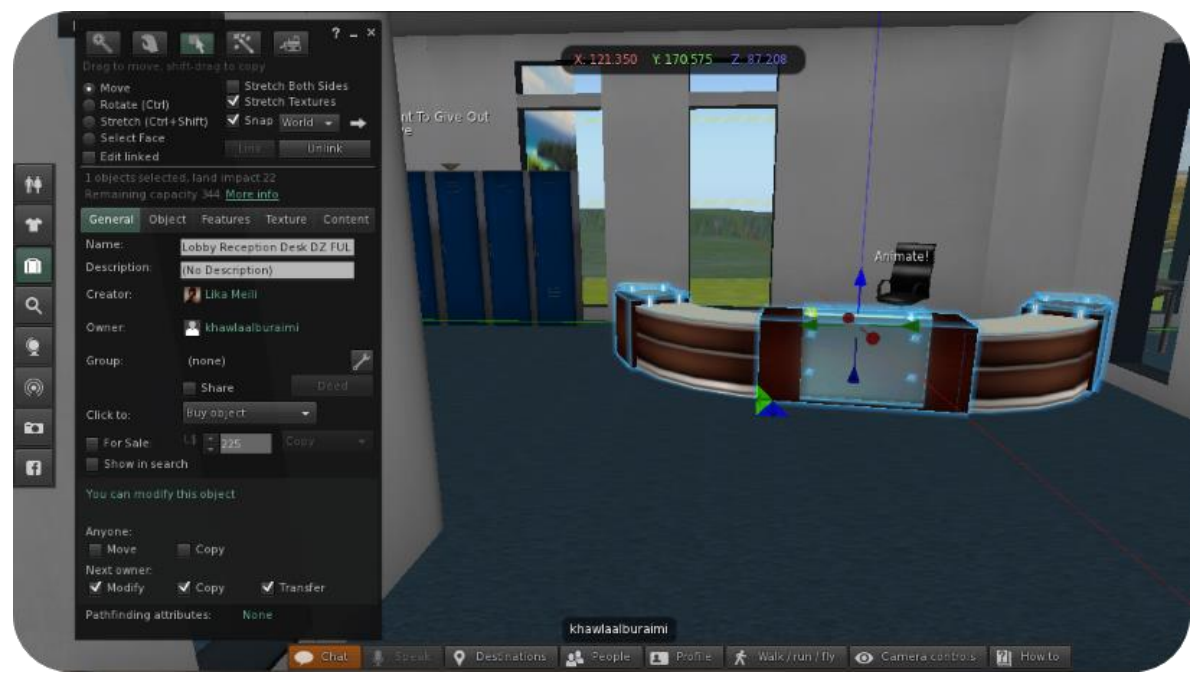

Fig. 13: A screenshot of the reception desk being moved into the right position 
Ahmad F. Shubita and Ghassan F. Issa / Journal of Computer Science 2019, 15 (10): 1498.1509 DOI: 10.3844/jessp.2019.1498.1509

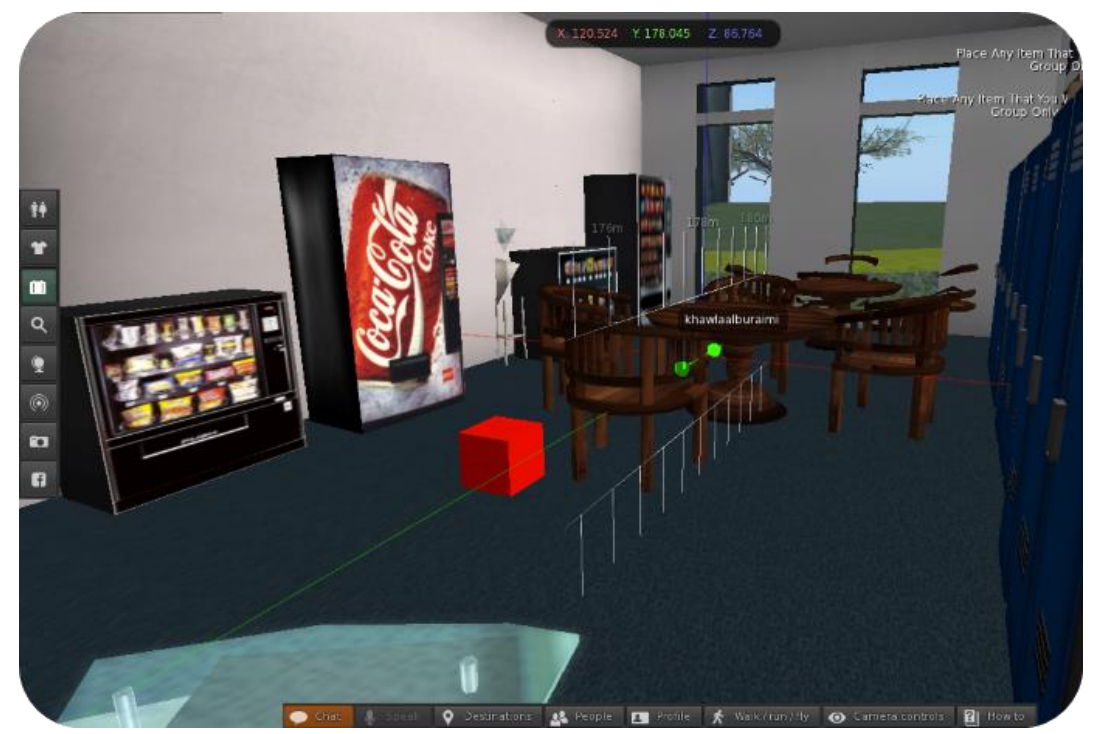

Fig. 14: A screenshot of the tables being placed in the lounge area

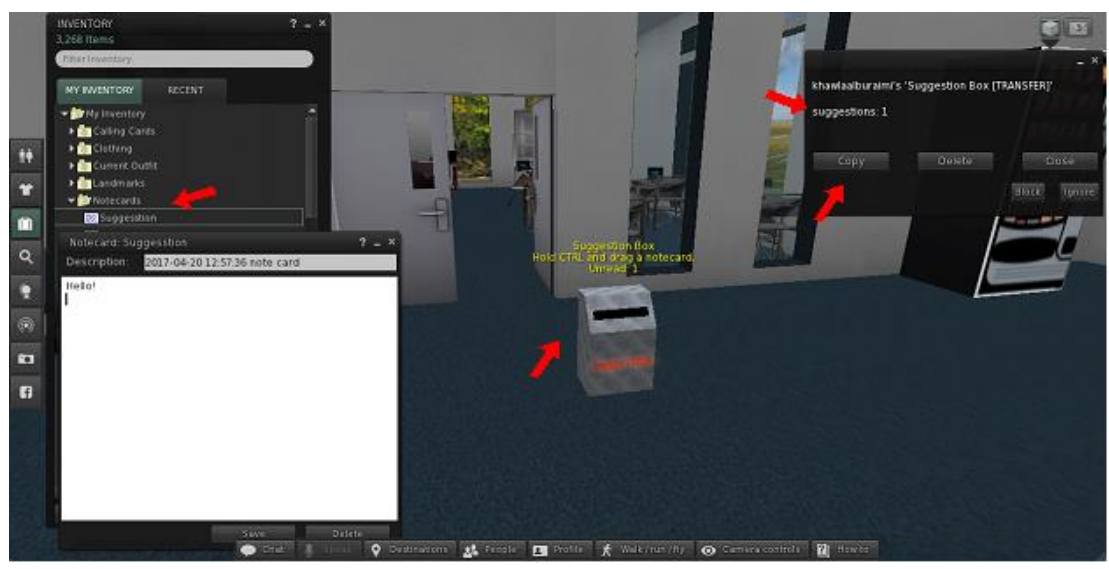

Fig. 15: A screenshot showing a test of the suggestion box before it was placed on the wall

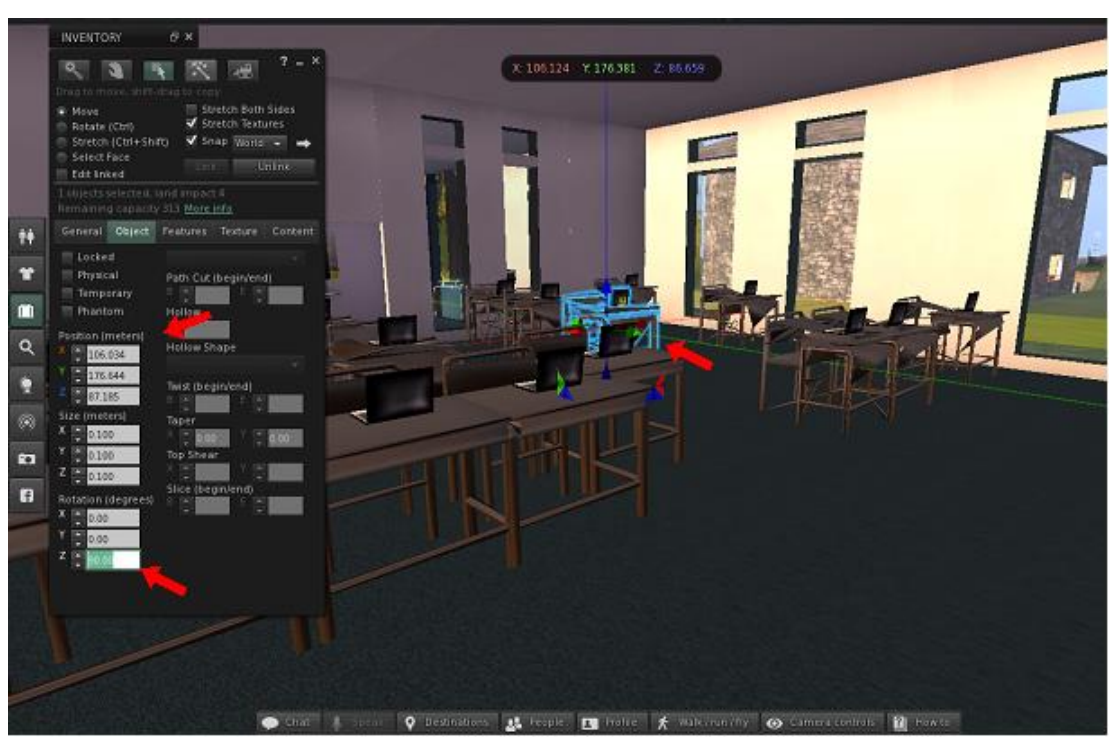

Fig. 16: A screenshot showing the arranging of the student desks in the classroom 
For the suggestion box shown in Fig. 15, the team tried using it before placing it on the wall. To add a suggestion, the user has to create a notecard from the inventory and then drag it to the suggestion box. As stated before, the box is placed high-up on a wall near reception so everyone can see it.

In the classroom (Fig. 16 and 18), the desks are arranged to look like the real UOP college classroom with three desks on each side. Like a real UOP classroom (Fig. 17), there is a smart board, a white board and teacher's desk with its chair.

\section{Virtual Campus: Testing and Results}

Based on the client's requirements and the success criteria, the virtual campus was placed on a small area of land that fit the building and had space left for future expansion. One of the success criteria was to be able to accept feedback and allow comments and suggestions, therefore, a suggestion box is placed near the reception to allow anyone to submit feedback and suggestions. The results were based on a sample group of 100 students who visited and used the virtual campus.

\section{Goal 1}

To provide a variety of services for students, visitors and employees of the Information Technology College.

\section{Measurement}

Time devoted to providing educational services to students shall be reduced by $10 \%$.

\section{Input}

Provide a variety of services for students, visitors and employees of the Information Technology College.

\section{Output}

The time that is devoted by providing the services of educational reduced by $10 \%$. This output was reached by calculating the time given for each student of the sample group (100 students) and compare it with the time given to provide the same service in the real campus (Fig. 21).

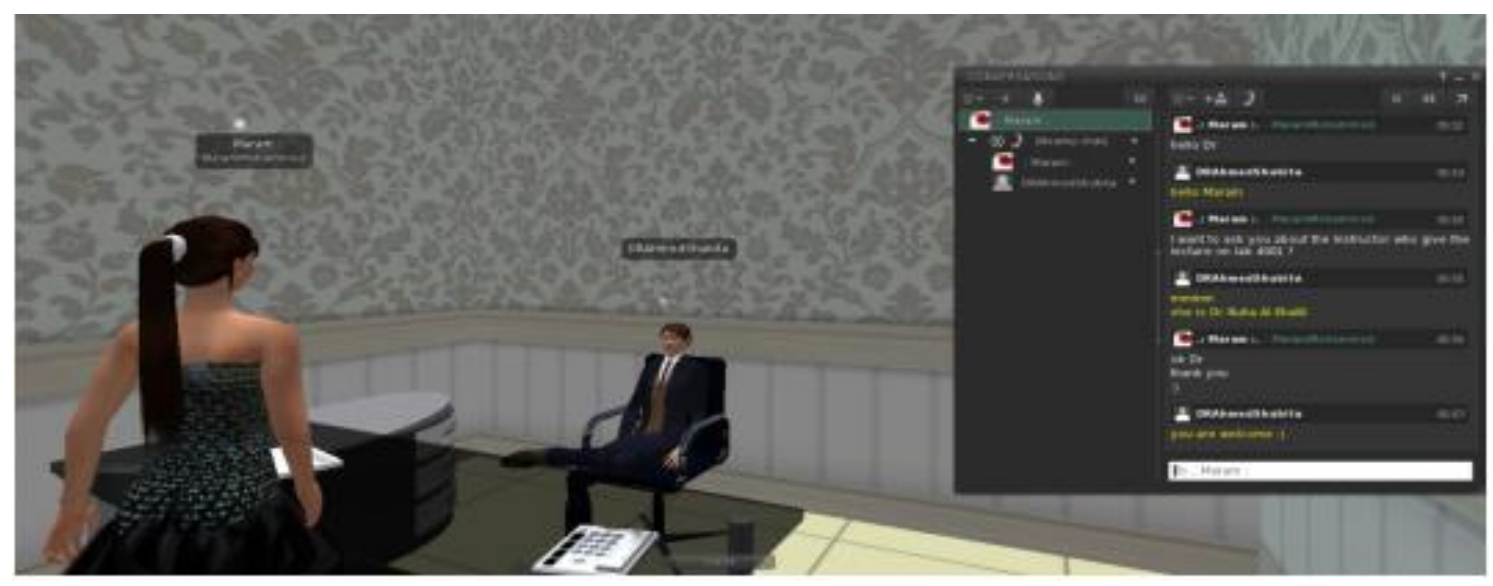

Fig. 17: A screenshot showing the provision of educational services to students

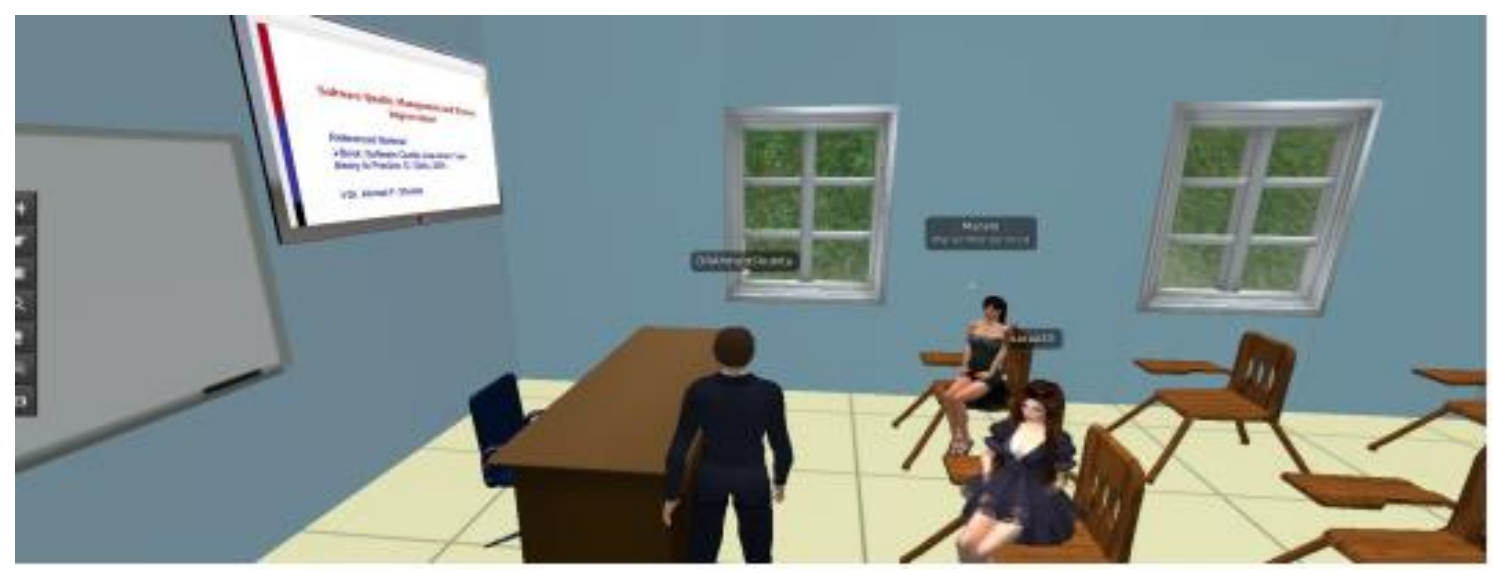

Fig. 18: A screenshot of students being taught in the virtual classroom 


\section{Goal 2}

Increasing communication and discussions possibilities on a wide scale.

\section{Measurement}

Increasing communication between users by up to $50 \%$ using different communication tools.

\section{Output}

Communication and discussions increased by $50 \%$.
This output was reached by calculating the communication and discussions happened between a sample group of 100 students and college staff by using the chatting and voice functions (Fig. 19 and 20) on the virtual campus. The results were compared with the number of discussions between the same parties on the real campus. A notable increase in the number of discussions between both students and staff/students and students was observed on the virtual campus.

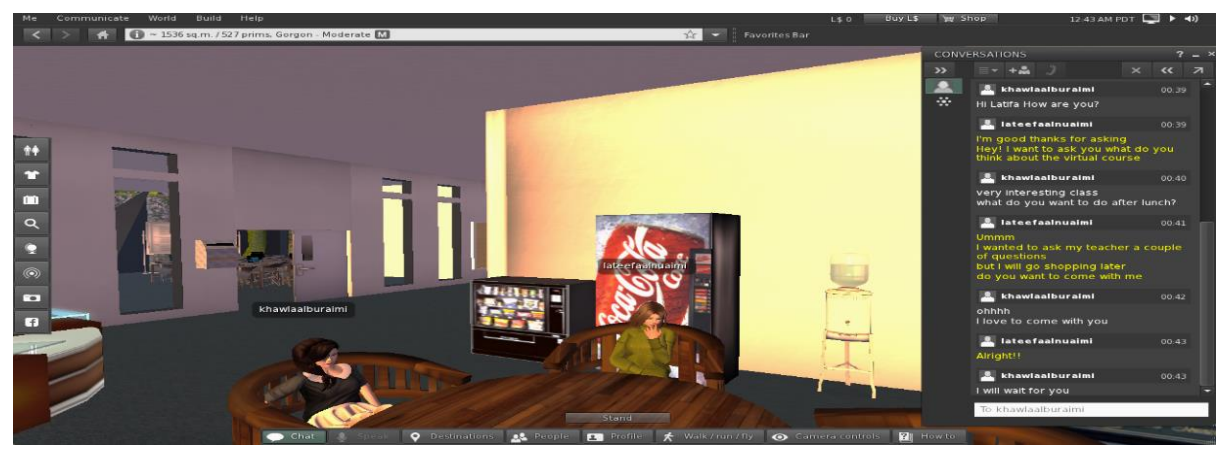

Fig. 19: A screenshot showing two students chatting in the lounge area

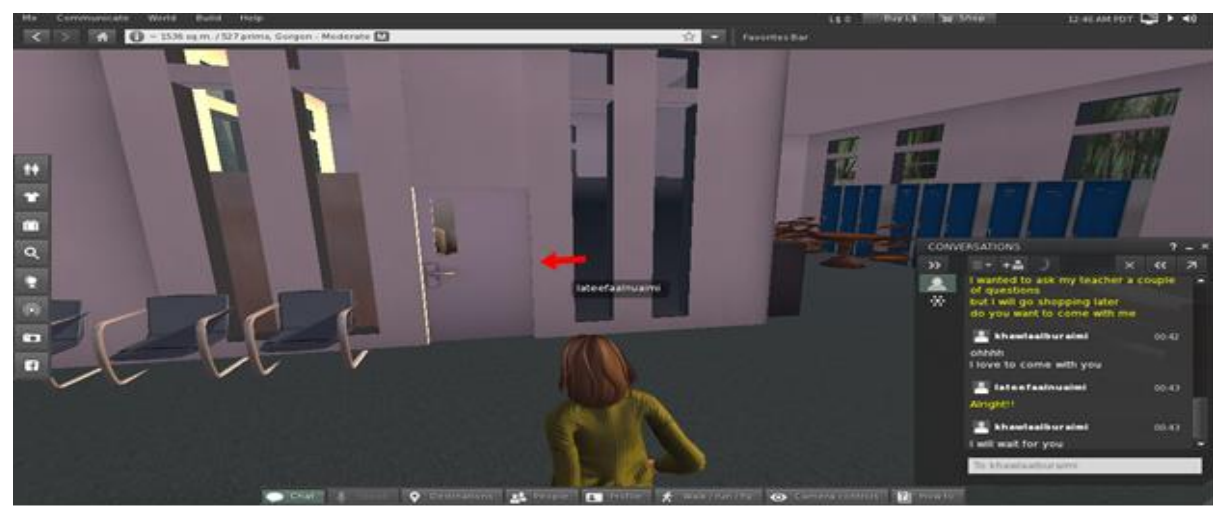

Fig. 20: A screenshot of a student having a conversation with a staff member

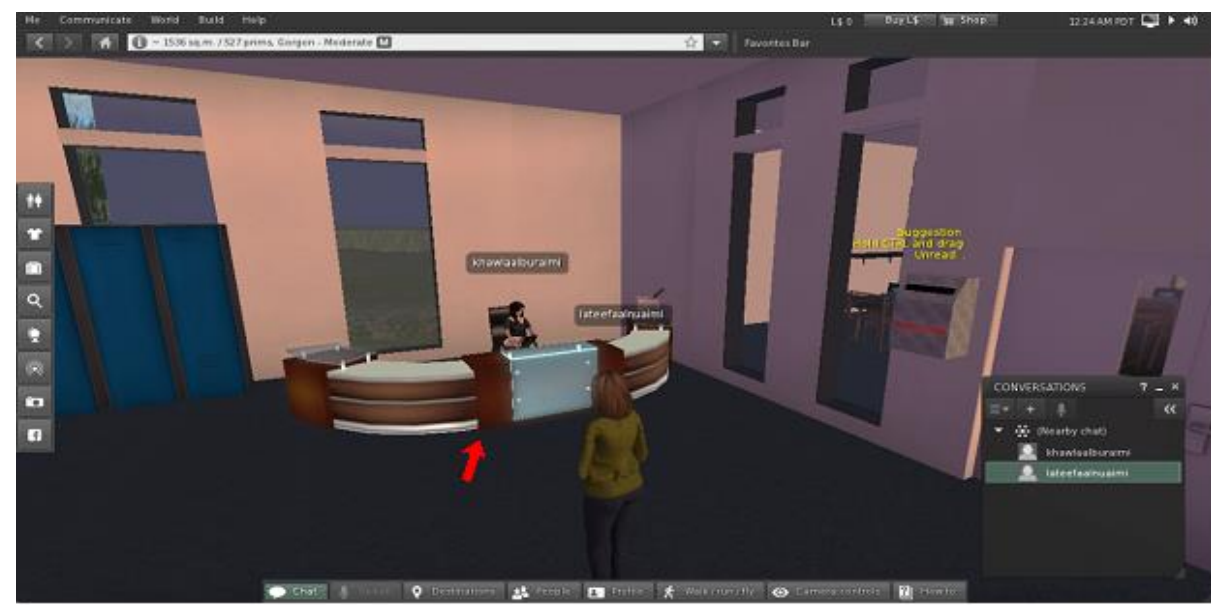

Fig. 21: A screenshot of a student approaching the receptionist 


\section{Goal 3}

To advertise Petra University and increase the number of visitors.

\section{Measurement}

Increasing University of Petra advertising by $5 \%$ worldwide.

\section{Conclusion}

SL provides rich communication, the collaboration between virtual and 3-D creations and the potential for teaching and learning. It should also be noted that reaching the University of Petra in the real world takes more time, effort and money than using SL. This project was the first applied in the Middle East and by using SL for educational purposes, the capacity and efficiency of University of Petra are increased.

Overcoming some of the drawbacks of SL was a massive challenge for this study. The most obvious drawback of SL is the time it takes to obtain the skills needed to interact with others. The students needed time to learn how to operate within SL and the instructors needed to employ new skills and techniques. In this study, the usability problem was reduced by adding multiple help messages to support the users while using the virtual campus. In addition, an expert person/avatar was assigned at the reception of the virtual campus to help the users and make their experience easier. By adding those features, the time the students and teachers took to learn the fundamental skills needed for SL was massively reduced. However, some technology related drawbacks were difficult to overcome. SL needs highspeed internet availability to operate correctly and efficiently. Overcoming this challenge could be done by using a lite version of SL in the future.

SL provides a great opportunity for educational institutions who want a virtual presence so they can reach a wider range of people, e.g., those with special needs or difficult circumstances. As the first virtual campus in Jordan, it was a privilege to open the door to a variety of learning experiences. Building the virtual campus was an overall success as the fully developed prototype meets the given requirements while maintaining the project constraints.

One aspect that needs further development is the provision of more security on the land. Another future development plan is to build a Student Services desk to increase the number of virtual service. Overall, SL is a different world with a whole new environment and community that allow people to live a virtual life.

\section{Acknowledgment}

The authors gratefully acknowledge support provided by the Faculty of Information Technology at the University of Petra, Jordan.

\section{Author's Contributions}

Ahmad F. Shubita: Contributed in all experiments, coordinated the data analysis and contributed to the writing of the manuscript, designed the research plan and organized the study.

Ghassan F. Issa: Coordinated the mouse work, contributed to the writing of the manuscript.

\section{Ethics}

The authors address any ethical issues that may arise after the publication of this manuscript.

\section{References}

Alenezi, A.M. and K.K. Shahi, 2015. Interactive elearning through second life with blackboard technology. Proc. Soc. Behav. Sci., 176: 891-897. DOI: 10.1016/j.sbspro.2015.01.555

Boulos, M.N.K., L. Hetherington and S. Wheeler, 2007. Second life: An overview of the potential of 3-D virtual worlds in medical and health education. Health Inform. Libraries, 24: 233-245. DOI: $10.1111 / j .1471-1842.2007 .00733 . x$

Collins, C. and R.W. Millard, 2008. Galapagos islands in second life.

Gallego, M.D., 2016. Second life adoption in education: A motivational model based on uses and gratifications theory. Comput. Educ., 100: 81-93. DOI: 10.1016/j.compedu.2016.05.001

HKPU, 2011. PolyU Virtual Campus. Hong Kong Polytechnic University.

Inman, C., V.H. Wright and J.A. Hartman, 2009. Use of second life in K-12 and higher education: A review of research. J. Interactive Online Learn., 9: 44-63.

Ketelhut, D.J., C. Dede, J. Clarke, B. Nelson and C. Bowman, 2006. Studying situated learning in a multi-user virtual environment. Harvard Graduate School of Education

Linden Lab, 2011. Second life education: The virtual learning advantage. San Francisco.

Livingstone, D. and J. Kemp, 2006. Proceedings of the second life education workshop at the second life community convention. Fort Mason Centre, San Francisco, Ca.

Memikoğlu, İ., 2014. Utilization of second life as a tool for spatial learning in interior architecture. Proc. Soc. Behav. Sci., 116: 1288-1292.

DOI: 10.1016/j.sbspro.2014.01.384

Merchant, Z., 2014. Effectiveness of virtual reality-based instruction on students' learning outcomes in K-12 and higher education: A meta-analysis. Comput. Educ., 70: 29-40.

DOI: 10.1016/j.compedu.2013.07.033 
Shubati, A., C.W. Dawson and R.J. Dawson, 2009. A Methodology for Developing Second Life Environment Using Case-Based Reasoning. Proceedings of the Software Quality Management XVII: Software Quality in the 21st Century, (SQC' 09), Southampton, UK, pp: 155-166.

Shubati, A., C.W. Dawson and R.J. Dawson, 2011. Artefact generation in second life with case-based reasoning. Software Quality J., 19: 431-446. DOI: $10.1007 / \mathrm{s} 11219-010-9125-4$

Shubati, A., R.J. Dawson and C.W. Dawson, 2010. A second life development tool using feedback for continuous improvement. Proceedings of Software Quality Management XVIII: Quality Issues for Today, (QIT’ 10), Southampton, UK, pp: 135-146.

Varvello, M., C. Diot and E. Biersack, 2009. P2P second life: Experimental validation using Kad. Proceedings of the IEEE INFOCOM, Apr. 19-25, IEEE Xplore Press, Rio de Janeiro, Brazil, pp: 1161-1169. DOI: 10.1109/INFCOM.2009.5062029
Varvello, M., S. Ferrari, E. Biersack and C. Diot, 2011. Exploring second life. IEEE/ACM Trans. Network., 19: 80-91. DOI: 10.1109/TNET.2010.2060351

Vincent, P., 2017. How should BA define scope. Corporate Education Group.

Wang, F., 2013. Second life in education: A review of publications from its launch to 2011. Brit. J. Educ. Technol., 44: 357-371. DOI: $10.1111 / \mathrm{j} .1467-8535.2012 .01334 . \mathrm{x}$

Wright, M.K. and C.S. Wilhelmina, 2011. Using second life for educational purposes: An evaluation of a new workshop. 